Pacific Journal of Mathematics

CONTINUOUS DEPENDENCE FOR TWO-POINT BOUNDARY 


\section{CONTINUOUS DEPENDENCE FOR TWO-POINT BOUNDARY VALUE PROBLEMS}

\section{ROBERT GaINES}

\section{Suppose the boundary value problem}

$$
\begin{gathered}
y^{\prime \prime}=f\left(t, y, y^{\prime}\right) \\
y(a)=\alpha, \quad y(b)=\beta,
\end{gathered}
$$

where $f\left(t, y, y^{\prime}\right)$ is defined on $D \equiv[\alpha, b] \times R^{2}$, has a unique solution $y(t ; \alpha, \beta)$ which belongs to $C^{2}[a, b]$, for each $(\alpha, \beta)$ in some set $S \subset R^{2}$. This paper gives sufficient conditions for $y(t ; \alpha, \beta)$, $y^{\prime}(t ; \alpha, \beta)$, and $y^{\prime \prime}(t ; \alpha, \beta)$ to be continuous on $[a, b] \times S$.

In $\S 2$ it is shown that if $f\left(t, y, y^{\prime}\right)$ is continuous on $D$ and $y(t$; $\alpha, \beta)$ is continuous on $[a, b] \times S$, then $y^{\prime}(t ; \alpha, \beta)$ and $y^{\prime \prime}(t ; \alpha, \beta)$ are continuous on $[a, b] \times S$. In $\S 3$ it is shown that $y(t ; \alpha, \beta)$ is continuous under the assumption that solutions to boundary value problems for (1.1) exist and are unique in a certain strong sense. In $\S 4$ the continuity of $y(t ; \alpha, \beta)$ is established under the assumption that solutions to (1.1) satisfy a maximum principle.

Bebernes [1], Fountain and Jackson [3], and others have given sufficient conditions for the problem (1.1), (1.2) to have a unique solution, but the question of continuous dependence has not been given extensive attention.

2. Derivatives of convergent sequences. In this section we establish that if $f\left(t, y, y^{\prime}\right)$ is continuous on $D$, the continuity of $y(t ; \alpha, \beta)$ is enough to guarantee the continuity of $y^{\prime}(t ; \alpha, \beta)$ and $y^{\prime \prime}(t ; \alpha, \beta)$. The proof makes use of a lemma concerning derivatives of uniformly convergent sequences of solutions. First we prove a variation of a well-known result for initial value problems; e.g., see [4], p. 11.

Lemma 2.1. Let $f\left(t, y, y^{\prime}\right)$ be continuous on $D$. Given $T>0$ there exists $\alpha(T)>0$ such that if $y(t)$ is a solution to $(1.1)$ on $[a, b]$ and $\left|y\left(t_{0}\right)\right|+\left|y^{\prime}\left(t_{0}\right)\right| \leqq T$ for some $t_{0} \in[a, b]$, then $|y(t)|+\left|y^{\prime}(t)\right| \leqq 2 T$ for

$$
t \in \Delta\left(t_{0}, \alpha(T)\right) \equiv[a, b] \cap\left[t_{0}-\alpha(T), t_{0}+\alpha(T)\right] .
$$

Proof. Let

$$
K \equiv\left\{\left(t, y, y^{\prime}\right) \in D:|y|+\left|y^{\prime}\right| \leqq 2 T\right\}
$$

and let

$$
C \equiv \max _{K}\left|f\left(t, y, y^{\prime}\right)\right|+2 T
$$


Choose $\alpha(T)<T / C$.

Suppose for contradiction that $y(t)$ is a solution to $(1.1)$ on $[a, b]$ with $\left|y\left(t_{0}\right)\right|+\left|y^{\prime}\left(t_{0}\right)\right| \leqq T$ and there exists $t_{1} \in \Delta\left(t_{0}, \alpha(T)\right)$ such that

$$
\left|y\left(t_{1}\right)\right|+\left|y^{\prime}\left(t_{1}\right)\right|>2 T .
$$

For definiteness assume $t_{1}>t_{0}$. There exists $t_{2} \in \Delta\left(t_{0}, \alpha(T)\right)$ such that $t_{0}<t_{2}<t_{1}$,

$$
\left|y\left(t_{2}\right)\right|+\left|y^{\prime}\left(t_{2}\right)\right|=2 T
$$

and

$$
|y(t)|+\left|y^{\prime}(t)\right| \leqq 2 T
$$

for $t \in\left[t_{0}, t_{2}\right]$.

By the Mean Value Theorem

$$
\begin{aligned}
& \left|y\left(t_{2}\right)-y\left(t_{0}\right)\right|+\left|y^{\prime}\left(t_{2}\right)-y^{\prime}\left(t_{0}\right)\right| \\
& \quad=\left(\left|y^{\prime}\left(\zeta_{1}\right)\right|+\left|y^{\prime \prime}\left(\zeta_{2}\right)\right|\right)\left(t_{2}-t_{0}\right)
\end{aligned}
$$

for some $\zeta_{1}$ and $\zeta_{2}$ in $\left[t_{0}, t_{2}\right]$. By (2.2), $\left|y^{\prime}\left(\zeta_{1}\right)\right| \leqq 2 T$. Moreover, (2.2) yields that $\left(\zeta, y\left(\zeta_{2}\right), y^{\prime}\left(\zeta_{2}\right)\right) \in K$ and we have

$$
\left|y^{\prime \prime}\left(\zeta_{2}\right)\right|=\left|f\left(\zeta, y\left(\zeta_{2}\right), y^{\prime}\left(\zeta_{2}\right)\right)\right| \leqq \max _{K}\left|f\left(t, y, y^{\prime}\right)\right|
$$

Thus

$$
\begin{aligned}
\left|y\left(t_{2}\right)-y\left(t_{0}\right)\right|+\left|y^{\prime}\left(t_{2}\right)-y^{\prime}\left(t_{0}\right)\right| & \leqq\left(2 T+\max _{K}\left|f\left(t, y, y^{\prime}\right)\right|\right)\left(t_{2}-t_{0}\right) \\
& \leqq C \alpha(T) \\
& <T
\end{aligned}
$$

hence,

$$
\left|y\left(t_{2}\right)\right|+\left|y^{\prime}\left(t_{2}\right)\right|<T+\left|y\left(t_{0}\right)\right|+\left|y^{\prime}\left(t_{0}\right)\right| \leqq 2 T .
$$

This contradicts (2.1).

LemMA 2.2. Let $f\left(t, y, y^{\prime}\right)$ be continuous on $D$ and let $\left\{y_{n}(t)\right\}$ be a sequence of solutions to (1.1) on $[a, b]$ such that $y_{n}(t) \rightarrow y_{0}(t)$ uniform$l y$ on $[a, b]$ and $y_{0}(t)$ has a continuous derivative on $[a, b]$. If there exists a sequence $\left\{t_{n}\right\}$ in $[a, b]$ such that $t_{n} \rightarrow t_{0}$ and $y_{n}^{\prime}\left(t_{n}\right) \rightarrow z_{0}$, then there exists a subsequence $\left\{y_{k(n)}(t)\right\}$ such that $y_{k(n)}^{\prime}(t) \rightarrow y_{0}^{\prime}(t)$ uniformly on $[a, b]$.

Proof. Let $T_{0} \equiv\left|y_{0}\left(t_{0}\right)\right|+\left|z_{0}\right|+1$. There exists $N>0$ such that

$$
\left|y_{n}\left(t_{n}\right)\right|+\left|y_{n}^{\prime}\left(t_{n}\right)\right| \leqq T_{0}
$$

for $n \geqq N$. By Lemma 2.1, there exists $\alpha\left(T_{0}\right)>0$ such that for $n \geqq N$ 


$$
\left|y_{n}(t)\right|+\left|y_{n}^{\prime}(t)\right| \leqq 2 T_{0}
$$

on $\Delta\left(t_{n}, \alpha\left(T_{0}\right)\right)$. Since $t_{n} \rightarrow t_{0}$, there exists $N_{0} \geqq N$ such that for $n \geqq N_{0}$

$$
\left|y_{n}(t)\right|+\left|y_{n}^{\prime}(t)\right| \leqq 2 T_{0}
$$

on $\Delta\left(t_{0}, \alpha\left(T_{0}\right) / 2\right)$.

Let

$$
K_{0} \equiv\left\{\left(t, y, y^{\prime}\right): t \in \Delta\left(t_{0}, \alpha\left(T_{0}\right) / 2\right),|y|+\left|y^{\prime}\right| \leqq 2 T_{0}\right\} .
$$

For $n \geqq N_{0}$ and $t \in \Delta\left(t_{0}, \alpha\left(T_{0}\right) / 2\right)$ we have

$$
\left|y_{n}^{\prime \prime}(t)\right|=\left|f\left(t, y_{n}(t), y_{n}^{\prime}(t)\right)\right| \leqq \max _{K_{0}}\left|f\left(t, y, y^{\prime}\right)\right|
$$

It follows from the Mean Value Theorem that $\left\{y_{n}^{\prime}(t)\right\}$ is equicontinuous on $\Delta\left(t_{0}, \alpha\left(T_{0}\right) / 2\right)$. Since $\left\{y_{n}^{\prime}(t)\right\}$ is bounded by $2 T_{0}$ on $\Delta\left(t_{0}, \alpha\left(T_{0}\right) / 2\right)$ for $n \geqq N_{0}$, Ascoli's Theorem implies that $\left\{y_{n}^{\prime}(t)\right\}$ has a subsequence $\left\{y_{k_{1}(n)}^{\prime}\right\}$ which converges uniformly on $\Delta\left(t_{0}, \alpha\left(T_{0}\right) / 2\right)$ to some $z_{0}(t)$. But since $y_{k_{1}(n)}(t) \rightarrow y_{0}(t)$ on $\Delta\left(t_{0}, \alpha\left(T_{0}\right) 2\right)$ we must have $z_{0}(t) \equiv y_{0}^{\prime}(t)$ on $\Delta\left(t_{0}, \alpha\left(T_{0}\right) / 2\right)$.

If $\Delta\left(t_{0}, \alpha\left(T_{0}\right) / 2\right)=[a, b]$ we are through. If not, at least one end point of $\Delta\left(t_{0}, \alpha\left(T_{0}\right) / 2\right)$ is in $(a, b)$. Denote such an end point by $t_{1}$.

Let $T \equiv \max _{[a, b]}\left(\left|y_{0}(t)\right|+\left|y_{0}^{\prime}(t)\right|\right)+1$.

There exists $N_{1}$ such that for $n \geqq N_{1}$

$$
\begin{aligned}
\left|y_{k_{1}(n)}\left(t_{1}\right)\right|+\left|y_{k_{1}(n)}^{\prime}\left(t_{1}\right)\right| & \leqq\left|y_{0}\left(t_{1}\right)\right|+\left|y_{0}^{\prime}\left(t_{1}\right)\right|+1 \\
& \leqq T .
\end{aligned}
$$

By Lemma 2.1 there exists $\alpha(T)$ such that

$$
\left|y_{k_{1}(n)}(t)\right|+\left|y_{k_{1}(n)}^{\prime}(t)\right| \leqq 2 T
$$

for $t \in \Delta\left(t_{1}, \alpha(T)\right)$ and $n \geqq N_{1}$. By the same arguments used for the interval $\Delta\left(t_{0}, \alpha\left(T_{0}\right) / 2\right),\left\{y_{k_{1}(n)}(t)\right\}$ has a subsequence $\left\{y_{k_{2}(n)}(t)\right\}$ such that $y_{k_{2}(n)}^{\prime}(t) \rightarrow y_{0}^{\prime}(t)$ uniformly on $\Delta\left(t_{1}, \alpha(T)\right)$. Thus $y_{k_{2}(n)}^{\prime}(t) \rightarrow y_{0}^{\prime}(t)$ uniformly on $\Delta\left(t_{1}, \alpha(T)\right) \cup \Delta\left(t_{0}, \alpha\left(T_{0}\right) / 2\right)$.

If $\Delta\left(t_{1}, \alpha(T)\right) \cup \Delta\left(t_{0}, \alpha\left(T_{0}\right) / 2\right)=[a, b]$ we are through. If not, there is an end point $t_{2}$ of $\Delta\left(t_{1}, \alpha(T)\right) \cup \Delta\left(t_{0}, \alpha\left(T_{0}\right) / 2\right)$ in $(a, b)$ and the above procedure may be repeated with $T$ unchanged. Since $\alpha(T)$ is also unchanged, this process will terminate in a finite number of steps with a subsequence $\left\{y_{k_{m}(n)}(t)\right\}$ such that $y_{k_{m}(n)}^{\prime}(t) \rightarrow y_{0}^{\prime}(t)$ uniformly on

$$
\Delta\left(t_{0}, \alpha\left(T_{0}\right) / 2\right) \cup\left\{\bigcup_{i=1}^{m-1} \Delta\left(t_{i}, \alpha(T)\right)\right\}=[a, b] .
$$

LEMma 2.3. Let $f\left(t, y, y^{\prime}\right)$ be continuous on $D$. If $\left\{y_{n}(t)\right\}$ is a sequence of solutions to (1.1) on $[a, b]$ such that $y_{n}(t) \rightarrow y_{0}(t)$ uniform$l y$ on $[a, b]$ where $y_{0}(t)$ has a continuous derivative on $[a, b]$, then 
$y_{n}^{\prime}(t) \rightarrow y_{0}^{\prime}(t)$ uniformly on $[a, b]$.

Proof. By the Mean Value Theorem, for each $n$ there exists $t_{n} \in[a, b]$ such that

$$
\left|y_{n}(b)-y_{n}(a)\right|=\left|y_{n}^{\prime}\left(t_{n}\right)\right|(b-a) .
$$

Since there exists $B>0$ such that $\left|y_{n}(t)\right| \leqq B$ on $[a, b]$ for all $n$, we have

$$
\left|y_{n}^{\prime}\left(t_{n}\right)\right| \leqq 2 B /(b-a) .
$$

Let $\left\{y_{k_{0}(n)}(t)\right\}$ denote an arbitrary subsequence of $\left\{y_{n}(t)\right\}$. Since $\left\{y_{k_{0}(n)}^{\prime}\left(t_{k_{0}(n)}\right)\right\}$ is bounded we may extract a further subsequence $\left\{y_{k_{1}(n)}(t)\right\}$ such that $y_{k_{1}(n)}^{\prime}\left(t_{k_{1}(n)}\right) \rightarrow z_{0}$ and $t_{k_{1}(n)} \rightarrow t_{0} \in[a, b]$. By Lemma 2.2, there exists a further subsequence $\left\{y_{k_{2}(n)}(t)\right\}$ such that $y_{k_{2}(n)}^{\prime}(t) \rightarrow y_{0}^{\prime}(t)$ uniformly on $[a, b]$.

Thus any subsequence of $\left\{y_{n}(t)\right\}$ has a further subsequence which has its derivatives converging uniformly to $y_{0}^{\prime}(t)$ on $[a, b]$. It follows that $y_{n}^{\prime}(t) \rightarrow y_{0}^{\prime}(t)$ uniformly on $[a, b]$.

The conclusion of Lemma 2.3 does not hold if the hypothesis that $y_{0}(t)$ has a continuous derivative on $[a, b]$ is removed. The function $y_{n}(t)=\sqrt{b+1 / n-t}$ is a solution to $y^{\prime \prime}=2\left(y^{\prime}\right)^{3}$ on $[0, b]$ for each $n$. Moreover, $\left\{y_{n}(t)\right\}$ converges to $y_{0}(t)=\sqrt{b-t}$ uniformly on $[o, b]$. But $\left\{y_{n}^{\prime}(t)\right\}$ does not converge to $y_{0}^{\prime}(t)$ uniformly on $[o, b]$.

Theorem 2.4. Let $f\left(t, y, y^{\prime}\right)$ be continuous on $D$. Suppose (1.1) has a unique solution $y(t ; \alpha, \beta)$ on $[a, b]$ satisfying $(1.2)$ for $(\alpha, \beta) \in S \subset$ $R^{2}$. If $y(t ; \alpha, \beta)$ is continuous on $[a, b] \times S$, then $y^{\prime}(t ; \alpha, \beta)$ and $y^{\prime \prime}(t ; \alpha, \beta)$ are continuous on $[a, b] \times S$.

Proof. Since $y^{\prime}(t ; \alpha, \beta)$ and $y^{\prime \prime}(t ; \alpha, \beta)$ are continuous for fixed $(\alpha, \beta)$,

$$
\begin{aligned}
& \left|y^{\prime}(t ; \alpha, \beta)-y^{\prime}\left(t_{0} ; \alpha_{0}, \beta_{0}\right)\right| \leqq\left|y^{\prime}(t ; \alpha, \beta)-y^{\prime}\left(t ; \alpha_{0}, \beta_{0}\right)\right| \\
& \quad+\left|y^{\prime}\left(t ; \alpha_{0}, \beta_{0}\right)-y^{\prime}\left(t_{0} ; \alpha_{0}, \beta_{0}\right)\right|
\end{aligned}
$$

and

$$
\begin{aligned}
& \left|y^{\prime \prime}(t ; \alpha, \beta)-y^{\prime \prime}\left(t_{0} ; \alpha_{0}, \beta_{0}\right)\right| \leqq\left|y^{\prime \prime}(t ; \alpha, \beta)-y^{\prime \prime}\left(t ; \alpha_{0}, \beta_{0}\right)\right| \\
& \quad+\left|y^{\prime \prime}\left(t ; \alpha_{0}, \beta_{0}\right)-y^{\prime \prime}\left(t_{0} ; \alpha_{0}, \beta_{0}\right)\right|
\end{aligned}
$$

it is sufficient to show that $y^{\prime}(t ; \alpha, \beta)$ and $y^{\prime \prime}(t ; \alpha, \beta)$ are continuous functions of $\alpha$ and $\beta$ uniformly with respect to $t$.

Let $\left(\alpha_{n}, \beta_{n}\right)$ be a sequence in $S$ such that $\left(\alpha_{n}, \beta_{n}\right) \rightarrow\left(\alpha_{0}, \beta_{0}\right) \in S$. Since $y(t ; \alpha, \beta)$ is continuous on $[a, b] \times S, y\left(t, \alpha_{n}, \beta_{n}\right) \rightarrow y\left(t ; \alpha_{0}, \beta_{0}\right)$ uniformly on $[a, b]$; hence, Lemma 2.3 yields the uniform convergence 
of $\left\{y^{\prime}\left(t ; \alpha_{n}, \beta_{n}\right)\right\}$ to $y^{\prime}\left(t ; \alpha_{0}, \beta_{0}\right)$. Since

$$
y^{\prime \prime}\left(t ; \alpha_{n}, \beta_{n}\right)=f\left(t, y\left(t ; \alpha_{n}, \beta_{n}\right), y^{\prime}\left(t ; \alpha_{n}, \beta_{n}\right)\right)
$$

and $f\left(t ; y, y^{\prime}\right)$ is continuous, it follows that $y^{\prime \prime}\left(t ; \alpha_{n}, \beta_{n}\right) \rightarrow y^{\prime \prime}\left(t ; \alpha_{0}, \beta_{0}\right)$ uniformly on $[a, b]$.

3. Strong existence and uniqueness. In this section we show that $y(t ; \alpha, \beta)$ is continuous on $[a, b] \times R^{2}$ if solutions to (1.1) exist and are unique in the sense described in the following definitions.

Definition. Solutions to boundary value problems for (1.1) will said to be unique in the strong sense on $[a, b]$ if for any solutions $\phi(t)$ and $\psi(t)$ to $(1.1)$ on $[c, d] \subset[a, b], \phi(c)=\psi(c)$ and $\phi(d)=\psi(d)$ imply that $\phi(t) \equiv \psi(t)$ on $[c, d]$.

Definition. Solutions to boundary value problems for (1.1) are be said to exist in the strong sense on $[a, b]$ if for any real numbers $\alpha$ and $\beta$ and any $[c, d] \subset[a, b]$ there is a solution $y(t)$ to (1.1) on an interval $I \supset[c, d]$ such that $y(c)=\alpha, y(d)=\beta$ and either

(i) $I=[a, b]$, or

(ii) $y(t)$ is unbounded.

THEOREM 3.1. Suppose solutions to boundary value problems for (1.1) exist and are unique in the strong sense on $[a, b]$. If $y(t ; \alpha, \beta)$ denotes the unique solution to (1.1) on $[a, b]$ satisfying (1.2), then $y(t ; \alpha, \beta)$ is continuous on $[a, b] \times R^{2}$.

Proof. Let $\varepsilon>0$ be given.

Let $t_{0} \in(a, b)$. Let $y_{1}(t)$ denote a solution to (1.1) on an interval $I_{1} \supset\left[t_{0}, b\right]$ such that

$$
y_{1}\left(t_{0}\right)=y\left(t_{0} ; \alpha_{0}, \beta_{0}\right)+\varepsilon, y_{1}(b)=y\left(b ; \alpha_{0}, \beta_{0}\right)=\beta_{0}
$$

and either $y_{1}(t)$ is unbounded or $I_{1}=[a, b]$. Let $y_{2}(t)$ denote a solution on $I_{2} \supset\left[a, t_{0}\right]$ such that

$$
y_{2}(a)=\left\{\begin{array}{l}
y_{1}(a), \text { if } I_{1}=[a, b] \\
y\left(a ; \alpha_{0}, \beta_{0}\right)+\varepsilon, \text { if } I_{1} \subset(a, b],
\end{array} \quad y_{2}\left(t_{0}\right)=y\left(t_{0} ; \alpha_{0}, \beta_{0}\right)+2 \varepsilon\right.
$$

and either $y_{2}(t)$ is unbounded or $I_{2}=[a, b]$.

Let $y_{3}(t)$ and $y_{4}(t)$ denote similar solutions on $I_{3} \supset\left[t_{0}, b\right]$ and $I_{4} \supset\left[a, t_{0}\right]$ with

$$
y_{3}\left(t_{0}\right)=y\left(t_{0} ; \alpha_{0}, \beta_{0}\right)-\varepsilon, \quad y_{3}(b)=y\left(b ; \alpha_{0}, \beta_{0}\right)=\beta_{0}
$$


(3.4) $y_{4}(a)=\left\{\begin{array}{l}y_{3}(a), \text { if } I_{3}=[a, b] \\ y\left(a ; \alpha_{0}, \beta_{0}\right)-\varepsilon, \text { if } I_{3} \subset(a, b],\end{array} \quad y_{4}\left(t_{0}\right)=y\left(t_{0} ; \alpha_{0}, \beta_{0}\right)-2 \varepsilon\right.$.

Assume for definiteness that $I_{1}=[a, b], I_{2} \subset[a, b), I_{3} \subset(a, b]$, and $I_{4}=[a, b]$. The other cases may be treated with arguments similar to those below.

Uniqueness in the strong sense and (3.1) imply that

$$
y_{1}(a)=y_{2}(a)>\alpha_{0}=y\left(a ; \alpha_{0}, \beta_{0}\right) \text {. }
$$

Since $y_{2}\left(t_{0}\right)>y_{1}\left(t_{0}\right)$ follows from (3.2), uniqueness in the strong sense also implies that $y_{2}(t) \geqq y_{1}(t)$ on $I_{2}$; hence, $y_{2}(t)$ must become unbounded positively to the right of $t_{0}$.

Uniqueness in the strong sense and (3.3) imply that $y_{3}(t) \leqq y\left(t ; \alpha_{0}, \beta_{0}\right)$ on $I_{3}$; hence, $y_{3}(t)$ must become unbounded negatively to the left of $t_{0}$. Since $y_{4}\left(t_{0}\right)<y_{3}\left(t_{0}\right)$, there exists $a<t_{1}<t_{0}$ such that $y_{4}\left(t_{1}\right)=y_{3}\left(t_{1}\right)$; hence, uniqueness in the strong sense implies that $y_{4}(t)<y_{3}(t)$ on $\left[t_{0}, b\right]$. In particular, $y_{4}(b)<y_{3}(b)=\beta_{0}=y\left(b ; \alpha_{0}, \beta_{0}\right)$.

Let $\delta_{1}\left(t_{0}\right) \equiv \min \left[y_{2}(a)-\alpha_{0}, \alpha_{0}-y_{4}(a), \beta_{0}-y_{4}(b)\right]$. If $\left|\alpha-\alpha_{0}\right|+$ $\left|\beta-\beta_{0}\right|<\delta_{1}\left(t_{0}\right)$, then $y_{4}(\alpha)<\alpha<y_{2}(a)$ and $\beta>y_{4}(b)$. By uniqueness in the strong sense we must have $y_{4}(t) \leqq y(t ; \alpha, \beta)$ on $[a, b]$ and since $y_{2}(t)$ becomes unbounded positively to the right of $t_{0}$ we must also have $y(t ; \alpha, \beta) \leqq y_{2}(t)$ on $I_{2}$.

There exists $\delta_{2}\left(t_{0}\right)$ such that for

$$
\left|t-t_{0}\right|<\delta_{2}\left(t_{0}\right), t \in I_{2},\left|y_{2}(t)-y_{2}\left(t_{0}\right)\right|<\varepsilon,
$$

and $\left|y_{4}(t)-y_{4}\left(t_{0}\right)\right|<\varepsilon$. Thus, for $\left|\alpha-\alpha_{0}\right|+\left|\beta-\beta_{0}\right|<\delta_{1}\left(t_{0}\right)$ and $\left|t-t_{0}\right|<\delta_{2}\left(t_{0}\right)$ we have

$$
\begin{aligned}
\left|y(t ; \alpha, \beta)-y\left(t ; \alpha_{0}, \beta_{0}\right)\right| \leqq & y_{2}(t)-y_{4}(t) \\
\leqq & \left|y_{2}(t)-y_{2}\left(t_{0}\right)\right|+y_{2}\left(t_{0}\right)-y_{4}\left(t_{0}\right) \\
& +\left|y_{4}(t)-y_{4}\left(t_{0}\right)\right| \\
\leqq & \varepsilon+4 \varepsilon+\varepsilon=6 \varepsilon .
\end{aligned}
$$

Uniqueness in the strong sense implies that for

$$
\begin{aligned}
& \left|\alpha-\alpha_{0}\right|+\left|\beta-\beta_{0}\right|<\delta_{1}(\alpha)=\delta_{1}(b) \equiv \varepsilon, \\
& \quad y\left(t ; \alpha_{0}-\varepsilon, \beta_{0}-\varepsilon\right) \leqq y(t ; \alpha, \beta) \leqq y\left(t ; \alpha_{0}+\varepsilon, \beta_{0}+\varepsilon\right)
\end{aligned}
$$

on $[a, b]$. There exists $\delta_{2}(a)$ such that for $|t-a|<\delta_{2}(a)$

$$
\left|y\left(t ; \alpha_{0}+\varepsilon, \beta_{0}+\varepsilon\right)-y\left(\alpha ; \alpha_{0}+\varepsilon, \beta_{0}+\varepsilon\right)\right|<\varepsilon
$$

and

$$
\left|y\left(t ; \alpha_{0}-\varepsilon, \beta_{0}-\varepsilon\right)-y\left(\alpha ; \alpha_{0}-\varepsilon, \beta_{0}-\varepsilon\right)\right|<\varepsilon .
$$

Thus for $\left|\alpha-\alpha_{0}\right|+\left|\beta-\beta_{0}\right|<\delta_{1}(a)$ and $|t-a|<\delta_{2}(a)$ 


$$
\left|y(t ; \alpha, \beta)-y\left(t ; \alpha_{0}, \beta_{0}\right)\right| \leqq 6 \varepsilon .
$$

A $\delta_{2}(b)$ may be defined in a similar manner.

By the Heine-Borel Theorem there exist $t_{1}, t_{2}, \cdots, t_{k}$ such that the intervals defined by $\left|t-t_{1}\right|<\delta_{2}\left(t_{i}\right)$ cover $[a, b]$. Let $\delta \equiv \min \delta_{1}\left(t_{i}\right)$. Then for any $t \in[a, b]\left|\alpha-\alpha_{0}\right|+\left|\beta-\beta_{0}\right|<\delta$ implies that

$$
\left|y(t ; \alpha, \beta)-y\left(t ; \alpha_{0}, \beta_{0}\right)\right| \leqq 6 \varepsilon .
$$

Since $y(t ; \alpha, \beta)$ is continuous for fixed $\alpha$ and $\beta$, it follows that $y(t ; \alpha, \beta)$ is continuous on $[a, b] \times R^{2}$.

It is of interest to note that in the proof of Theorem 3.1, the fact that the functions involved were solutions to (1.1) was used only to assert that the functions were continuous. The arguments may be applied to any family of continuous functions satisfying the uniqueness and existence requirements. Theorem 3.1 is a variation of a result of Beckenbach ([2], p. 365) concerning two-parameter families of continuous functions.

As an immediate consequence of Theorems 2.4 and 3.1 we have

Corollary 3.2. Let $f\left(t, y, y^{\prime}\right)$ be continuous on $D$ and suppose solutions to boundary value problems for (1.1) exist and are unique in the strong sense on $[a, b]$. If $y(t ; \alpha, \beta)$ denotes the unique solution to $(1.1)$ on $[a, b]$ satisfying $(1.2)$, then $y(t ; \alpha, \beta), y^{\prime}(t ; \alpha, \beta)$ and $y^{\prime \prime}(t ; \alpha, \beta)$ are continuous on $[a, b] \times R^{2}$.

4. The maximum principle. In this section we consider the function $y(t ; \alpha, \beta)$ in the presence of a maximum principle.

Definition. Solutions to (1.1) will be said to satisfy the maximum principle on $[c, d] \subset[a, b]$ if for any solutions $\phi(t)$ and $\psi(t)$ to (1.1) on $[c, d],|\phi(t)-\psi(t)|$ assumes its maximum on $[c, d]$ at either $c$ or $d$.

Note that if solutions to (1.1) satisfy the maximum principle on $[a, b]$, then solutions to $(1.1)$ on $[a, b]$ satisfying (1.2) are unique.

THEOREM 4.1. Suppose solutions to (1.1) satisfy the maximum principle on $[a, b]$. If (1.1) has a (unique) solution $y(t ; \alpha, \beta)$ on $[a, b]$ satisfying (1.2) for $(\alpha, \beta) \in S \subset R^{2}$, then $y(t ; \alpha, \beta)$ is continuous on $[a, b] \times S$.

Proof. By the maximum principle on $[a, b]$, for $(\alpha, \beta)$ and $\left(\alpha_{0}, \beta_{0}\right)$ in $S$ we have

$$
\left|y(t ; \alpha, \beta)-y\left(t ; \alpha_{0}, \beta_{0}\right)\right| \leqq \max \left[\left|\alpha-\alpha_{0}\right|,\left|\beta-\beta_{0}\right|\right] .
$$


Since $y(t ; \alpha, \beta)$ is continuous on $[a, b]$ for fixed $(\alpha, \beta)$, it follows that $y(t ; \alpha, \beta)$ is continuous on $[a, b] \times S$.

Corollary 4.2. Let $f\left(t, y, y^{\prime}\right)$ be continuous on $D$. Suppose solutions to (1.1) satisfy the maximum principle on $[a, b]$. If (1.1) has a (unique) solution $y(t ; \alpha, \beta)$ on $[a, b]$ satisfying $(1.2)$ for $(\alpha, \beta) \in S \subset R^{2}$, then $y(t ; \alpha, \beta), y^{\prime}(t ; \alpha, \beta)$ and $y^{\prime \prime}(t ; \alpha, \beta)$ are continuous on $[\alpha, b] \times S$.

Various sets of hypotheses on $f\left(t, y, y^{\prime}\right)$ imply that solutions to (1.1) satisfy the maximum principle. As an example we state

THEOREM 4.3. If $f\left(t, y, y^{\prime}\right)$ is continuous on $D, f\left(t, y, y^{\prime}\right)$ is nondecreasing in $y$ on $D$, and for any compact subset $C \subset D$ there is a positive constant $K(C)$ such that

$$
\left|f\left(t, y, y_{1}^{\prime}\right)-f\left(t, y, y_{2}^{\prime}\right)\right| \leqq K(C)\left|y_{1}^{\prime}-y_{2}^{\prime}\right|
$$

for any $\left(t, y, y_{1}^{\prime}\right)$ and $\left(t, y, y_{2}^{\prime}\right)$ in $C$, then solutions to (1.1) satisfy the maximum principle on any $[c, d] \subset[a, b]$.

Proof. This is an immediate consequence of Theorem 2.2 in [1].

As a partial converse to Theorem 4.3, we have

THEOREM 4.4. If $f\left(t, y, y^{\prime}\right)$ is continuous on $D$ and solutions to (1.1) satisfy the maximum principle on every $[c, d] \subset[a, b]$, then $f\left(t, y, y^{\prime}\right)$ is nondecreasing in $y$ on $D$.

Proof. Suppose for contradiction there exist $\left(t_{0}, y_{1}, y_{0}^{\prime}\right)$ and $\left(t_{0}, y_{2}, y_{0}^{\prime}\right)$ in $D$ such that $y_{1}>y_{2}$ and $f\left(t_{0}, y_{1}, y_{0}^{\prime}\right)<f\left(t_{0}, y_{2}, y_{0}^{\prime}\right)$. By continuity we may assume $t_{0} \in(a, b)$.

Since $f\left(t, y, y^{\prime}\right)$ is continuous on $D$, there exists an interval $\left[c_{0}, d_{0}\right] \subset[a, b]$ with $t_{0} \in\left(c_{0}, d_{0}\right)$ such that (1.1) has solutions $y_{1}(t)$ and $y_{2}(t)$ on $\left[c_{0}, d_{0}\right]$ with $y_{1}\left(t_{0}\right)=y_{1}, y_{1}^{\prime}\left(t_{0}\right)=y_{0}^{\prime}, y_{2}\left(t_{0}\right)=y_{2}$, and $y_{2}^{\prime}\left(t_{0}\right)=y_{0}^{\prime}$. Since

$$
y_{1}^{\prime \prime}\left(t_{0}\right)-y_{2}^{\prime \prime}\left(t_{0}\right)=f\left(t_{0}, y_{1}, y_{0}^{\prime}\right)-f\left(t_{0}, y_{2}, y_{0}^{\prime}\right)<0,
$$

$y_{1}^{\prime}\left(t_{0}\right)-y_{2}^{\prime}\left(t_{0}\right)=0$, and $y_{1}\left(t_{0}\right)-y_{2}\left(t_{0}\right)>0$, there exists $[c, d] \subset\left[c_{0}, d_{0}\right]$ such that $t_{0} \in(c, d)$ and $y_{1}\left(t_{0}\right)-y_{2}\left(t_{0}\right)>y_{1}(t)-y_{2}(t) \geqq 0$ for any $t \neq t_{0}$ in $[c, d]$. In particular,

$$
y_{1}\left(t_{0}\right)-y_{2}\left(t_{0}\right)>\max \left[\left|y_{1}(c)-y_{2}(c)\right|,\left|y_{1}(d)-y_{2}(d)\right|\right]
$$


which contradicts the maximum principle being satisfied on $[c, d]$.

5. Continuous dependence without uniqueness in the strong sense. Though the hypotheses of Theorem 4.1 only required that solutions satisfy the maximum principle on $[a, b]$, a more "natural" assumption is that solutions satisfy the maximum principle on every subinterval $[c, d]$. If this stronger assumption is made, solutions to (1.1) are unique in the strong sense as was assumed in the hypothesis of Theorem 3.1.

A simple example shows that uniqueness in the strong sense is not a necessary condition for continuous dependence. Consider the equation

$$
y^{\prime \prime}=-y \text {. }
$$

The unique solution to $(5.1)$ on $[a, b] \equiv[0,3 \pi / 2]$ satisfying

$$
y(0)=\alpha, y(3 \pi / 2)=\beta
$$

is

$$
y(t ; \alpha, \beta)=\alpha \cos t-\beta \sin t
$$

which is clearly a continuous function of $\alpha, \beta$ and $t$. However, $y_{1}(t) \equiv 0$ and $y_{2}(t) \equiv \sin t$ are both solutions to $(5.1)$ on $[0, \pi]$ with $y_{1}(0)=$ $y_{2}(0)=0$ and $y_{1}(\pi)=y_{2}(\pi)=0$.

When strong uniqueness is not present and in other situations, the following theorem suggested to the author by A. M. Fink is sometimes useful.

Theorem 5.1. Let $f\left(t, y, y^{\prime}\right)$ be continuous on $D$. Suppose (1.1) has a unique solution $y(t ; \alpha, \beta)$ on $[a, b]$ satisfying $(1.2)$ for $(\alpha, \beta)$ in a subset $S \subset R^{2}$. If there exists $B>0$ such that $|y(t ; \alpha, \beta)| \leqq B$ and $\left|y^{\prime}(t ; \alpha, \beta)\right| \leqq B$ for $(t, \alpha, \beta)$ in $[a, b] \times S$, then $y(t, \alpha, \beta), y^{\prime}(t ; \alpha, \beta)$, and $y^{\prime \prime}(t ; \alpha, \beta)$ are continuous on $[a, b] \times S$.

Proof. Since $f\left(t, y, y^{\prime}\right)$ is continuous and

$$
y^{\prime \prime}(t ; \alpha, \beta)=f\left(t, y(t ; \alpha, \beta), y^{\prime}(t ; \alpha, \beta)\right)
$$

there exists $M>0$ such that $\left|y^{\prime \prime}(t ; \alpha, \beta)\right| \leqq M$ for $(t, \alpha, \beta) \in[a, b] \times S$.

Let $\left\{\left(\alpha_{n}, \beta_{n}\right)\right\}$ be a sequence in $S$ such that $\left(\alpha_{n}, \beta_{n}\right) \rightarrow\left(\alpha_{0}, \beta_{0}\right) \in S$. Let $\left\{y\left(t ; \alpha_{k(n)}, \beta_{k(n)}\right)\right\}$ denote an arbitrary subsequence of $\left\{y\left(t ; \alpha_{n}, \beta_{n}\right)\right\}$. Since $\left|y^{\prime}\left(t ; \alpha_{k(n)}, \beta_{k(n)}\right)\right| \leqq B$ and $\left|y^{\prime \prime}\left(t ; \alpha_{k(n)}, \beta_{k(n)}\right)\right| \leqq M$, the Mean Value Theorem implies that $\left\{y\left(t ; \alpha_{k(n)}, \beta_{k(n)}\right)\right\}$ and $\left\{y^{\prime}\left(t ; \alpha_{k(n)}, \beta_{k(n)}\right)\right\}$ are equicontinuous. Since both sequence are also uniformly bounded, using Ascoli's Thorem we may choose a further subsequence $\left\{y\left(t ; \alpha_{k_{1}(n)}, \beta_{k_{1}(n)}\right)\right\}$ 
such that $y\left(t ; \alpha_{k_{1}(n)}, \beta_{k_{1}(n)}\right) \rightarrow y_{0}(t)$ and $y^{\prime}\left(t ; \alpha_{k_{1}(n)}, \beta_{k_{1}(n)}\right) \rightarrow y_{0}^{\prime}(t)$ uniformly on $[a, b]$ for some $y_{0}(t)$. Since $f\left(t, y, y^{\prime}\right)$ is continuous, it follows from (5.3) that $\left\{y^{\prime \prime}\left(t ; \alpha_{k_{1}(n)}, \beta_{k_{1}(n)}\right)\right\}$ converges to $y_{0}^{\prime \prime}(t)$ and $y_{0}(t)$ is a solution to $(1.1)$ on $[a, b]$. Since $y_{0}(a)=\alpha$ and $y_{0}(b)=\beta$, uniqueness implies that $y_{0}(t) \equiv y\left(t ; \alpha_{0}, \beta_{0}\right)$.

It follows that the original sequences must converge to the same limits; i.e.,

$$
y\left(t ; \alpha_{n}, \beta_{n}\right) \rightarrow y\left(t ; \alpha_{0}, \beta_{0}\right), \quad y^{\prime}\left(t ; \alpha_{n}, \beta_{n}\right) \rightarrow y^{\prime}\left(t ; \alpha_{0}, \beta_{0}\right),
$$

and $y^{\prime \prime}\left(t ; \alpha_{n}, \beta_{n}\right) \rightarrow y^{\prime \prime}\left(t ; \alpha_{0}, \beta_{0}\right)$ uniformly on $[a, b]$; hence, $y(t ; \alpha, \beta)$, $y^{\prime}(t ; \alpha, \beta)$ and $y^{\prime \prime}(t ; \alpha, \beta)$ are continuous on $[a, b] \times S$.

If a Nagumo growth condition of the type introduced in [5] and employed to obtain existence in [1] and [3] is imposed, then bounds on derivatives may be obtained whenever the solutions themselves are bounded.

\section{REFERENCES}

1. J. W. Bebernes, A subfunction approach to a boundary value problem for ordinary differential equations, Pacific J. Math. 13 (1963), 1053-1066.

2. E. F. Beckenbach, Generalized convex functions, Bull. Amer. Math. Soc. 43 (1937), 363-371.

3. L. Fountain and L. Jackson, A generalized solution of the boundary value problem for $y^{\prime \prime}=f\left(x, y, y^{\prime}\right)$, Pacific J. Math. 12 (1962), 1251-1272.

4. P. Hartman, Ordinary differential equations, John Wiley and Sons, New York, (1964).

5. V. M. Nagumo, Uber die Differentialgleichung $y^{\prime \prime}=f\left(x, y, y^{\prime}\right)$, Proc. Physics-Math. Soc. Japan (3) 19 (1937) 861-866.

Received September 8, 1967. Portions of this paper are part of a doctoral thesis written under the supervision of Professor Jerrold Bebernes at the University of Colorado and supported by a NASA Traineeship.

Colorado State University 


\section{PACIFIC JOURNAL OF MATHEMATICS}

\section{EDITORS}

H. ROYDEN

Stanford University

Stanford, California

\section{R. $R$ PHELPS}

University of Washington

Seattle, Washington 98105

\section{J. DugunduI}

Department of Mathematics

University of Southern California

Los Angeles, California 90007

RICHARD ARENS

University of California

Los Angeles, California 90024

\section{ASSOCIATE EDITORS}

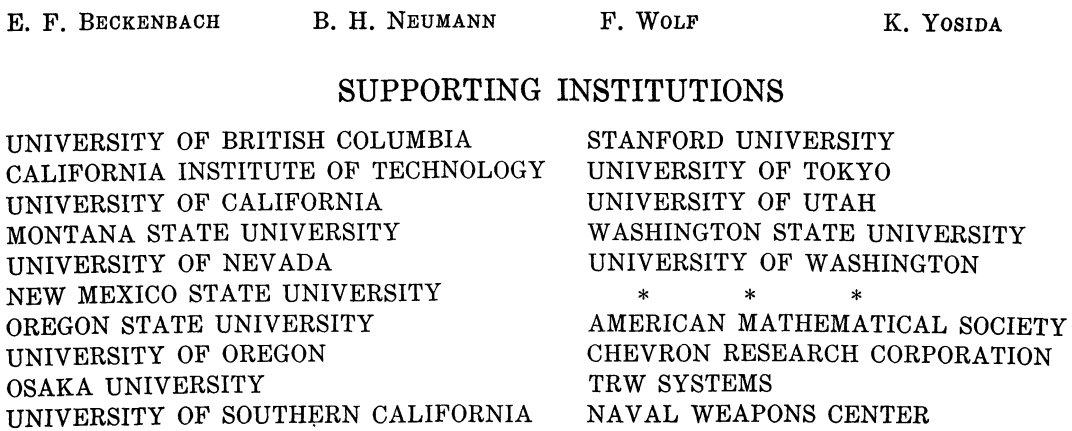

The Supporting Institutions listed above contribute to the cost of publication of this Journal, but they are not owners or publishers and have no responsibility for its content or policies.

Mathematical papers intended for publication in the Pacific Journal of Mathematics should be in typed form or offset-reproduced, double spaced with large margins. Underline Greek letters in red, German in green, and script in blue. The first paragraph or two must be capable of being used separately as a synopsis of the entire paper. It should not contain references to the bibliography. Manuscripts, in duplicate if possible, may be sent to any one of the four editors. Please classify according to the scheme of Math. Rev. 36, 1539-1546. All other communications to the editors should be addressed to the managing editor, Richard Arens, University of California, Los Angeles, California, 90024.

50 reprints are provided free for each article; additional copies may be obtained at cost in multiples of 50 .

The Pacific Journal of Mathematics is published monthly. Effective with Volume 16 the price per volume (3 numbers) is $\$ 8.00$; single issues, $\$ 3.00$. Special price for current issues to individual faculty members of supporting institutions and to individual members of the American Mathematical Society: $\$ 4.00$ per volume; single issues $\$ 1.50$. Back numbers are available.

Subscriptions, orders for back numbers, and changes of address should be sent to Pacific Journal of Mathematics, 103 Highland Boulevard, Berkeley, California, 94708.

PUBLISHED BY PACIFIC JOURNAL OF MATHEMATICS, A NON-PROFIT CORPORATION

Printed at Kokusai Bunken Insatsusha (International Academic Printing Co., Ltd.), 7-17, Fujimi 2-chome, Chiyoda-ku, Tokyo, Japan. 


\section{Pacific Journal of Mathematics}

Vol. 28, No. $2 \quad$ April, 1969

Richard Arens and Donald George Babbitt, The geometry of relativistic

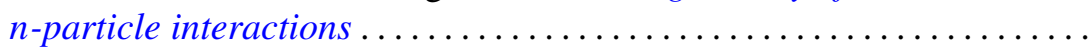

Kirby Alan Baker, Hypotopological spaces and their embeddings in lattices

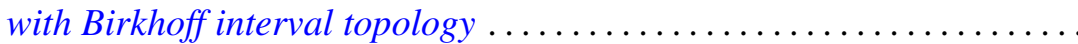

J. Lennart (John) Berggren, Finite groups in which every element is conjugate to its inverse ........................... 289

Beverly L. Brechner, Homeomorphism groups of dendrons . . . . . . . . . . . 295

Robert Ray Colby and Edgar Andrews Rutter, QF - 3 rings with zero singular ideal ................................. 303

Stephen Daniel Comer, Classes without the amalgamation property....... 309

Stephen D. Fisher, Bounded approximation by rational functions ......... 319

Robert Gaines, Continuous dependence for two-point boundary value problems..................................... 327

Bernard Russel Gelbaum, Banach algebra bundles ............... 337

Moses Glasner and Richard Emanuel Katz, Function-theoretic degeneracy criteria for Riemannian manifolds ...................... 351

Fletcher Gross, Fixed-point-free operator groups of order $8 \ldots \ldots \ldots \ldots 357$

Sav Roman Harasymiv, On approximation by dilations of distributions . . . . 363

Cheong Seng Hoo, Nilpotency class of a map and Stasheff's criterion ... . . 375

Richard Emanuel Katz, A note on extremal length and modutus.......... 381

H. L. Krall and I. M. Sheffer, Difference equations for some orthogonal polynomials ................................

Yu-Lee Lee, On the construction of lower radical properties ........... 393

Robert Phillips, Liouville's theorem........................... 397

Yum-Tong Siu, Analytic sheaf cohomology groups of dimension $n$ of

n-dimensional noncompact complex manifolds ..... . .

Michael Samuel Skaff, Vector valued Orlicz spaces. II...

James DeWitt Stein, Homomorphisms of $B^{*}$-algebras .... . .

Mark Lawrence Teply, Torsionfree injective modules .... . . .

Richard R. Tucker, The $\delta^{2}$-process and related topics. II .

David William Walkup and Roger Jean-Baptiste Robert Wets, Lifting

projections of convex polyhedra...

Thomas Paul Whaley, Large sublattices of a lattice. 